\title{
Parâmetros genéticos, dissimilaridade e desempenho per se em acessos de abóbora
}

\author{
Mariane G Ferreira; Felipe V Salvador; Mariana NR Lima; Alcinei M Azevedo; Izaias S Lima Neto; \\ Fábio M Sobreira; Derly JH Silva \\ Universidade Federal de Viçosa (UFV), Viçosa-MG, Brasil; mari.ferreira1010@gmail.com; felipe.vsalvador@gmail.com; mari. \\ netorosa@hotmail.com; alcineimistico@hotmail.com; izaiasneto@hotmail.com; fabiomsobreira@yahoo.com.br; derlyufv@gmail.com
}

\begin{abstract}
RESUMO
A abóbora tem grande importância na alimentação humana e animal, principalmente para a agricultura familiar. O banco de germoplasma de hortaliças da Universidade Federal de Viçosa (BGH-UFV) possui coleção de acessos de abóbora com ampla variabilidade genética. Toda esta variabilidade genética é de grande importância para o melhoramento genético. Porém, pouco se sabe sobre o verdadeiro potencial do BGH-UFV, pois há poucos estudos com informações desses acessos. Objetivou-se obter informações sobre os parâmetros genéticos, dissimilaridade e desempenho per se de acessos de abóbora do BGH-UFV. Foram avaliados 11 descritores morfoagronômicos em 55 acessos e três cultivares comerciais. Foram estimados parâmetros genéticos, ganho esperado com a seleção, correlações fenotípicas, genotípicas e ambientais. Para o estudo de dissimilaridade, foi realizado o teste Tocher e dispersão gráfica das duas primeiras variáveis canônicas. Houve variabilidade genética entre os acessos, com predominância dos efeitos genéticos sobre os ambientais. É esperado maior ganho de seleção para a massa por fruto, aspecto fitossanitário e localização do nó da primeira flor masculina. As cultivares comerciais Butternut e Tetsukabuto se destacaram em função da menor massa por fruto e maior precocidade de florescimento, porém tiveram os piores resultados quanto ao aspecto fitossanitário. Há estimativas negativas de correlação entre o aspecto fitossanitário com o hábito de crescimento, comprimento e taxa de crescimento da rama principal, indicando que plantas compactas podem ter maiores problemas fitossanitários. O cruzamento do acesso BGH-7003 ou da cultivar Butternut com os acessos BGH-1946 ou BGH-7765 podem gerar progênies com potencial para o melhoramento genético.
\end{abstract}

Palavras-chave: Cucurbita moschata, pré-melhoramento, recursos genéticos, análise multivariada, parâmetros genéticos.

\begin{abstract}
Genetic parameters, dissimilarity and performance of pumpkin accessions

Pumpkin is very important in human and animal food, especially concerning family farms. The germplasm bank of vegetables of Universidade Federal de Viçosa (Federal University of Viçosa, UFV-BGH), Brazil, has several pumpkin accessions with wide genetic variability. All this genetic variability is of great importance for plant breeding. However, little is known about the true potential of BGH-UFV, because there are few scientific papers published with information on these accessions. The objective was to obtain information on genetic parameters, dissimilarity and performance of BGH-UFV pumpkin accessions. We evaluated 11 morphological descriptors of 55 accessions and three cultivars. The genetic parameters, expected gain with selection, phenotypic, genotypic and environmental correlations were estimated. For the dissimilarity study, the Tocher test was carried out and graphic dispersion of the canonical variables was evaluated. There was genetic variability among accessions, with a predominance of genetic effects over the environment. Higher gain selection for mass per fruit, plant appearance and location of the first male flower node are expected. The commercial cultivars Butternut and Tetsukabuto have excelled due to the lower mass per fruit and precocity of flowering, but they had the worst results in terms of phytosanitary aspect. There are negative correlation estimates between the phytosanitary aspect and growth habit, length and growth rate of the main stem, indicating that compact plants may have greater phytossanitary problems. Crossing accession BGH-7003 or cultivar Butternut with accessions BGH-1946 or BGH-7765 can generate progenies with potential for breeding.
\end{abstract}

Keywords: Cucurbita moschata, pre-breeding, genetic resources, multivariate analysis, genetic parameters.

\section{(Recebido para publicação em 31 de março de 2015; aceito em 7 de março de 2016) (Received on March 31, 2015; accepted on March 7, 2016)}

\begin{abstract}
A abóbora (Cucurbita moschata) pertence à família Cucurbitácea, sendo de grande importância na alimentação humana e animal, principalmente para a agricultura familiar do Nordeste brasileiro. É fonte de minerais, fibras, vitaminas, nutrientes e antioxidantes (Aruah et al., 2012). Além disto, tem
\end{abstract}

grande importância social na geração de empregos diretos e indiretos, pois demanda mão-de-obra desde o cultivo até a comercialização (Resende et al., 2013). Cultivos comerciais da abóbora são encontrados em todo o Brasil, evidenciando a variabilidade desta espécie quanto à adaptabilidade às mais diversas condições edafoclimáticas (Blank et al., 2013). Em 2013, o volume de abóboras comercializado na CEAGESP-SP foi de 48,42 mil toneladas (Agrianual, 2015), evidenciando a importância econômica desta cultura.

O Brasil possui ampla variabilidade genética de abóbora armazenada e con- 
servada em bancos de germoplasma. Toda esta variabilidade genética é de grande importância para o melhoramento genético favorecendo a seleção de genitores com adequado desenvolvimento vegetativo, reprodutivo e com resistência a doenças. Ramos et al. (2000) relataram variabilidade e diversidade entre acessos de abóbora (C. moschata) pertencentes ao banco de germoplasma da Embrapa Semiárido para os descritores aplicados. Além disso, identificaram acessos promissores para constituir futuras populações em programas de melhoramento.

No Banco de Germoplasma de Hortaliças da Universidade Federal de Viçosa (BGH-UFV), as cucurbitáceas são representadas por cerca de $15,7 \%$ dos 6559 acessos registrados (Silva et al., 2001), sendo a maior parte acessos de abóbora. Embora o BGH-UFV possa ter acessos com potencial de utilização em programas de melhoramento, pouco se sabe sobre o seu verdadeiro potencial, pois há poucos estudos publicados com informações destes acessos.

Para o conhecimento do potencial de acessos para o melhoramento, a etapa de caracterização e avaliação é indispensável, permitindo o conhecimento da variabilidade genética existente e contribuindo para a identificação de genótipos promissores (Borges et al., 2011). Após a caracterização e avaliação de acessos é possível obter informações sobre o desempenho agronômico dos possíveis genitores, de parâmetros genéticos e da dissimilaridade genética entre os acessos (Cruz et al., 2012). Todas estas informações são importantes para os melhoristas, possibilitando a escolha das melhores estratégias para futuros programas de melhoramento (Azevedo et al., 2012).

Objetivou-se obter informações sobre os parâmetros genéticos, dissimilaridade e desempenho per se de acessos de abóbora do Banco de Germoplasma de Hortaliças da UFV (BGH-UFV).

\section{MATERIAL E MÉTODOS}

O experimento foi realizado na Horta Experimental do Departamento de Fitotecnia da Universidade Federal de Viçosa, localizada em Viçosa-MG (2045'14"'S; 42 52'53" O; 648,74 m de altitude), no período de janeiro a maio de 2011. Conforme classificação climática de Köppen, o clima regional é do tipo Cwb, mesotérmico úmido com verões chuvosos e invernos secos.

Foram avaliados 55 acessos de abóbora do Banco de Germoplasma de Hortaliças (BGH/UFV) e três cultivares comerciais como testemunhas [híbrido Tetsukabuto (Agristar) e as variedades Jacarezinho (ISLA Sementes) e Butternut (ISLA Sementes)]. As mudas foram produzidas em bandejas de poliestireno expandido de 72 células, contendo substrato comercial Tropstrato ${ }^{\circledR} \mathrm{e}$ transplantadas para o campo no estágio de primeira folha definitiva totalmente expandida, no espaçamento de $4 \times 3 \mathrm{~m}$. O solo foi previamente preparado por meio de gradagem, coveamento e adubação. A adubação foi realizada de acordo com a recomendação de adubação para o Estado de Minas Gerais (Ribeiro et al., 1999).

Os tratamentos foram alocados no delineamento em blocos ao acaso, com três repetições, cada parcela constituída por cinco plantas. Aplicaram-se os tratos culturais e fitossanitários recomendados para a cultura (Filgueira, 2007). Para o controle de pragas, além do tratamento químico, foram utilizadas armadilhas artesanais para a captura da mosca das frutas (Anastrepha fraterculus e Ceratitis capitata).

Foram avaliados os descritores hábito de crescimento, massa do fruto, dia para o florescimento e sanidade, propostos pelo International Plant Genetic Resources Institute (IPGRI) (Esquinas-Alcazar \& Gulick, 1893). Além destes descritores, foram considerados importantes do ponto de vista agronômico a avaliação dos caracteres comprimento da rama principal aos 35 dias após o transplantio, taxa de crescimento da rama principal, em cm/ dia, calculada semanalmente até 35 dias após o transplantio, número de ramas, número de ramificações da gavinha, localização do nó da primeira flor masculina, prolificidade. Na fase vegetativa, foram avaliados os caracteres: comprimento da rama principal aos 35 dias após o transplantio (CRP), taxa de crescimento da rama principal, em $\mathrm{cm} /$ dia, calculada semanalmente até 35 dias após o transplantio (TCRP), hábito de crescimento (HC), número de ramas (NR) e número de ramificações da gavinha (NRG). A avaliação do $\mathrm{HC}$ foi feita por escala de nota por três avaliadores previamente treinados utilizando-se a seguinte escala de notas: $1=$ arbustivo ou bush; $2=$ determinado (as plantas param de crescer durante o cultivo); $3=$ moderadamente indeterminado (as plantas não param de crescer durante o cultivo; menor porte entre as plantas de hábito indeterminado); $4=$ indeterminado (as plantas não param de crescer durante o cultivo; porte intermediário entre as plantas de hábito indeterminado); $5=$ excessivamente indeterminado (as plantas não param de crescer durante o cultivo; maior porte entre as plantas de hábito indeterminado). Como caracteres reprodutivos foram avaliados: número de dias para a abertura da primeira flor feminina (NDPFF), número de dias para a abertura da primeira flor masculina (NDPFM), localização do nó da primeira flor masculina (NóPFM), prolificidade - número de frutos por planta (PROL) e massa do fruto (MF).

Quanto ao aspecto fitossanitário (SANID), as plantas foram avaliadas sob condições naturais, no período de crescimento e maturação dos frutos (113 dias após o transplantio) por meio da seguinte escala de notas: $1=$ até $10 \%$ das folhas necrosadas por doenças; $2=$ de 11 a $25 \%$ das folhas necrosadas por doenças; $3=$ de 26 a $50 \%$ das folhas necrosadas por doenças; $4=$ de 51 a $75 \%$ das folhas necrosadas por doenças; e $5=$ acima de $75 \%$ das folhas necrosadas por doenças. Dentre os problemas fitossanitários, destacamse as doenças como a alternariose (Alternaria cucumerina), antracnose (Colletotrichum orbiculares), míldio (Pseudoperonospora cubensis), oídio (Podosphaera xanthii) que provocam desfolha precoce da planta, principalmente durante o período de crescimento e maturação dos frutos. As avaliações realizadas por escalas de notas foram realizadas independentemente por três avaliadores treinados, que atribuíram nota específica para cada planta. Desta forma, foi considerada 
para cada planta a média das notas dadas pelos três avaliadores.

O modelo estatístico considerado nas análises estatísticas foi:

$$
\mathrm{Y}_{\mathrm{ijk}}=\mathrm{m}+\mathrm{t}_{\mathrm{i}}+\mathrm{b}_{\mathrm{j}}+\mathrm{e}_{\mathrm{ij}}+\mathrm{d}_{\mathrm{ijk}}
$$

Em que $Y_{i j k}=$ observação referente ao k-ésimo indivíduo, do j-ésimo bloco, do i-ésimo acesso; $\mathrm{m}=$ média geral; $\mathrm{t}_{\mathrm{i}}=$ efeito do i-ésimo acesso $(i=1,2, \ldots, \mathrm{I})$ assumido como aleatório; $b_{j}=$ efeito do $\mathrm{j}$-ésimo bloco $(\mathrm{j}=1,2, \ldots, \mathrm{J})$ assumido como aleatório; $\mathrm{e}_{\mathrm{ij}}=$ efeito da interação entre o i-ésimo acesso e o j-ésimo bloco assumido como aleatório, $\mathrm{d}_{\mathrm{ijk}}=$ efeito do k-ésimo indivíduo dentro da ij-ésima parcela assumido como aleatório. Após verificar a pressuposição de normalidade e homocedasticidade pelos testes de Shapiro-Wilk e Bartlett, respectivamente, os dados foram submetidos à análise de variância. Quando identificado efeitos significativos pelo teste $\mathrm{F}$, foi realizado o teste de agrupamento de médias Scott-Knott. Foi considerado o nível nominal de significância de $5 \%$. Os parâmetros genéticos e as correlações fenotípicas, genotípicas e residuais foram obtidos pelos seguintes estimadores:

Herdabilidade no sentido amplo da média:

$$
h_{(\text {Média })}^{2}=\frac{\hat{\sigma}_{g}^{2}}{\hat{\sigma}_{g}^{2}+\frac{\hat{\sigma}_{e}^{2}}{J}+\frac{\hat{\sigma}_{d}^{2}}{\bar{K} J}}
$$

Herdabilidade no sentido amplo em nível de indivíduo no bloco:

$$
h_{(\text {Indiv_no_bloco })}^{2}=\frac{\hat{\sigma}_{g}^{2}}{\hat{\sigma}_{g}^{2}+\hat{\sigma}_{e}^{2}+\hat{\sigma}_{d}^{2}}
$$

Herdabilidade no sentido amplo em nível de indivíduo no experimento:

$$
h_{(\text {Indiv_no_exp) }}^{2}=\frac{\hat{\sigma}_{g}^{2}}{\hat{\sigma}_{g}^{2}+\hat{\sigma}_{b}^{2}+\hat{\sigma}_{e}^{2}+\hat{\sigma}_{d}^{2}}
$$

Coeficientes de variação ambiental 1:

$$
\mathrm{CV}_{1}(\%)=\frac{\sqrt{\text { QMentre } / \bar{K}}}{\hat{m}_{o}} \times 100
$$

Coeficientes de variação ambiental 2:

$$
\mathrm{CV}_{2}(\%)=\frac{\sqrt{\hat{\sigma}_{e}^{2}}}{\hat{m}_{o}} \times 100
$$

Coeficientes de variação genética:

$$
\mathrm{CV}_{\mathrm{g}}(\%)=\frac{\sqrt{\hat{\sigma}_{g}^{2}}}{\hat{m}_{o}} \times 100
$$

Índice de variação:

$$
\mathrm{I}_{\mathrm{v}}=\frac{\mathrm{CVg}}{\mathrm{CV}_{2}}
$$

Ganho de seleção:

$$
G S(\%)=\frac{h_{(\text {média })}^{2} \cdot\left(m_{m}-m_{o}\right)}{m_{o}} \times 100
$$

Coeficientes de correlação fenotípica:

$$
\mathrm{r}_{\mathrm{f}}=\frac{\sqrt{\operatorname{Cô}_{f}(\mathrm{X}, \mathrm{Y})}}{\sqrt{\hat{\sigma}_{\mathrm{f}}^{2}(\mathrm{X}) \cdot \hat{\sigma}_{\mathrm{f}}^{2}(\mathrm{Y})}}
$$

Coeficientes de correlação genotípica:

$$
\mathrm{r}_{\mathrm{g}}=\frac{\sqrt{\operatorname{CoV}(\mathrm{X}, \mathrm{Y})}}{\sqrt{\hat{\sigma}_{\mathrm{g}}^{2}(\mathrm{X}) \cdot \hat{\sigma}_{\mathrm{g}}^{2}(\mathrm{Y})}}
$$

Coeficientes de correlação ambiental:

$$
\mathrm{r}_{\mathrm{e}}=\frac{\sqrt{\mathrm{Co} \mathrm{V} e(\mathrm{X}, \mathrm{Y})}}{\sqrt{\hat{\sigma}_{\mathrm{e}}^{2}(\mathrm{X}) \cdot \hat{\sigma}_{\mathrm{e}}^{2}(\mathrm{Y})}}
$$

Em que: $\hat{\sigma}_{g}^{2}=$ variância genética, $\hat{\sigma}_{e}^{2}=$ variância residual entre, $\hat{\sigma}_{d}^{2}=$ variância residual dentro, $\hat{\sigma}_{b}^{2}=$ variância de blocos, $\hat{\sigma}_{f}^{2}=$ variância fenotípica; J é o número de repetições, $\bar{K}=$ média harmônica do número de plantas por parcela; $\mathrm{m}_{\mathrm{m}}=$ refere-se à média dos genótipos selecionados (15\% melhores); $\mathrm{m}_{\mathrm{o}}=$ média geral; CôVf $(\mathrm{X}, \mathrm{Y})$, CôVg $(\mathrm{X}, \mathrm{Y})$ e CôVe $(\mathrm{X}, \mathrm{Y})=$ estimativas da covariância fenotípica, genotípica e ambiental, respectivamente, entre dois caracteres X e Y.

$\mathrm{Na}$ análise estatística multivariada foi estimada a distância generalizada de Mahalanobis $\left(D_{i{ }^{\prime}}^{2}\right)$ para a aplicação do método de agrupamento de otimização de Tocher. Para a melhor visualização da dissimilaridade existente entre os acessos realizou-se a representação gráfica das duas primeiras variáveis canônicas. Para isso, foram desconsiderados os dados das variáveis comprimento da rama principal e hábito de crescimento, a fim de evitar a presença de multicolinearidade (número de condição superiores a 100 e fator de inflação de variância maior que 10). As análises uni e multivariadas foram realizadas utilizando-se o aplicativo genético-estatístico Genes (Cruz, 2013).

\section{RESULTADOS E DISCUSSÃO}

O efeito dos acessos foi significativo ao nível de $5 \%$ de probabilidade pelo teste $\mathrm{F}$ para as características comprimento da rama principal, taxa de crescimento da rama principal e número de ramas (Tabela 1). Para as demais características foi verificada significância ao nível de $1 \%$ de probabilidade. A significância para os efeitos dos genótipos indica a existência de variabilidade genética, e consequentemente, a possibilidade de selecionar acessos agronomicamente superiores para as características analisadas (Cruz et al., 2012).

Pelo coeficiente de variação genotípica verificam-se menores valores para as características número de ramos, número de ramificações da gavinha e número de dias para florescimento da primeira flor masculina. Já nas características massa do fruto e prolificidade foram observadas as maiores estimativas do coeficiente de variação genotípica. Bezerra Neto et al. (2006), avaliando linhagens de abóbora também verificaram maior coeficiente de variação genotípica para a característica massa de fruto em comparação com as demais características avaliadas. Maiores estimativas dos coeficientes de variação genotípica indicam a maior possibilidade de progressos genéticos com a seleção (Freitas et al., 2009).

As características prolificidade e massa do fruto tiveram o maior coeficiente de variação ambiental entre parcelas $\left(\mathrm{CVe}_{1}\right)$, o que indica que estas características são mais influenciáveis pelos efeitos ambientais (Tabela 1). Estes resultados contrariam os encontrados por Aruah et al. (2012) que encontraram baixas estimativas para o coeficiente de variação ambiental para a prolificidade $(9,17 \%)$. Quanto ao coeficiente de variação ambiental dentro $\left(\mathrm{CVe}_{2}\right)$, verificaram-se maiores estimativas para o comprimento da rama principal e taxa de crescimento da rama principal, indicando que para estas características houve maior variação dentro da parcela devido aos efeitos ambientais. Apenas as características comprimento da rama principal e taxa de crescimento da rama principal tiveram estimativas do índice 
Tabela 1. Estimativas de quadrados médios (QM), média harmônica do número de indivíduos por parcela (MHI), herdabilidade da média $\left(\mathrm{h}^{2}{ }_{\text {(média família) }}\right)$, herdabilidade do indivíduo no bloco $\left(\mathrm{h}^{2}{ }_{\text {(indiv no bloco) }}\right)$, herdabilidade do indivíduo no experimento $\left(\mathrm{h}^{2}{ }_{\text {(indiv no exp })}\right)$, coeficientes de variação do erro entre $\left(\mathrm{CVe}_{1}\right)$ e dentro $\left(\mathrm{CVe}_{2}\right)$, coeficiente de variação genética entre $\left(\mathrm{CVg}_{\text {entre }}\right)$, índices de variação entre $\left(\mathrm{CVg}_{\text {entre }} / \mathrm{CVe}\right)_{2}$ e ganho esperado com a seleção $\left[\mathrm{GS}_{\text {(média) }}(\%)\right]$ para 11 características avaliadas em 55 acessos de abóbora do BGH-UFV e três cultivares \{estimates of squares mean (QM), harmonic mean of the number of individuals per plot (MHI), heritability of the average $\left(\mathrm{h}^{2}{ }_{(\mathrm{mé} d i a}\right.$ familia) $\left.{ }\right)$, heritability of an individual in the block $\left(\mathrm{h}^{2}{ }_{\text {(indiv no bloco) }}\right)$, heritability of an individual in the experiment $\left(\mathrm{h}^{2}{ }_{\text {(indiv no exp })}\right)$, variation coefficients of error between $\left(\mathrm{CVe}_{1}\right)$ and within $\left(\mathrm{CVe}_{2}\right)$, genetic variation coefficient between $\left(\mathrm{CVg}_{\text {entre }}\right)$, variation rate between $\left(\mathrm{CVg}_{\text {entre }} / \mathrm{CVe}_{2}\right)$ and gain expected with the selection $\left[\mathrm{GS}_{\text {(média) }}(\%)\right]$ for 11 characteristics evaluated in 55 pumpkin accessions of BGH-UFV and three cultivars\}. Viçosa, UFV, 2011.

\begin{tabular}{|c|c|c|c|c|c|c|c|c|c|c|c|}
\hline Parân & CRP & TCRP & NDPFF & NDPFM & NóPFM & $\mathrm{HC}$ & NR & NRG & SANID & PROL & MF \\
\hline $\mathrm{QM}_{\text {Acesso }}$ & $2,29^{* *}$ & $29,28^{* *}$ & $665,20^{* *}$ & $196,67^{* *}$ & $52,65^{* *}$ & $2,18^{*}$ & $1,53^{*}$ & $0,92^{* *}$ & $4,57^{* *}$ & $34,36^{* *}$ & $59,60^{* *}$ \\
\hline $\mathrm{QM}_{\text {Bloco }}$ & $0,24^{\text {ns }}$ & $1,75^{\text {ns }}$ & $241,48^{\mathrm{ns}}$ & $99,72^{\mathrm{ns}}$ & $65,57^{\mathrm{ns}}$ & $2,66^{\mathrm{ns}}$ & $16,05^{* *}$ & $8,45^{* *}$ & $2,45^{\mathrm{ns}}$ & $67,10^{\text {ns }}$ & $1,10^{\text {ns }}$ \\
\hline $\mathrm{QM}_{\text {Entre }}$ & $1,38^{* *}$ & $17,63^{* *}$ & $106,57^{* *}$ & $42,47^{*}$ & $9,99^{\text {ns }}$ & $0,56^{* *}$ & $1,03^{\mathrm{ns}}$ & $0,43^{\mathrm{ns}}$ & $0,97^{\mathrm{ns}}$ & $9,47^{\mathrm{ns}}$ & $3,38^{\mathrm{ns}}$ \\
\hline $\mathrm{QM}_{\text {Dentro }}$ & 0,36 & 4,63 & 45,11 & 26,96 & 10,11 & 0,26 & 0,89 & 0,28 & 0,85 & 8,88 & 2,68 \\
\hline MHI & 4,96 & 4,96 & 4,78 & 4,86 & 4,85 & 2,97 & 2,98 & 2,99 & 3,00 & 3,00 & 2,84 \\
\hline Média geral & 2,79 & 9,77 & 45,31 & 44,12 & 6,27 & 3,72 & 5,12 & 3,31 & 3,26 & 6,19 & 4,29 \\
\hline $\mathrm{h}^{2}{ }_{\text {(Média) }}$ & 0,40 & 0,40 & 0,84 & 0,78 & 0,81 & 0,74 & 0,33 & 0,53 & 0,79 & 0,72 & 0,94 \\
\hline $\mathrm{h}_{\text {(Indiv no Bloco) }}^{2}$ & 0,10 & 0,10 & 0,40 & 0,26 & 0,23 & 0,33 & 0,06 & 0,14 & 0,31 & 0,23 & 0,69 \\
\hline $\mathrm{h}_{\text {(Indiv no Exp.) }}^{2}$ & 0,10 & 0,10 & 0,40 & 0,26 & 0,22 & 0,33 & 0,05 & 0,13 & 0,31 & 0,23 & 0,69 \\
\hline $\mathrm{CVe}_{1}$ & 18,90 & 19,28 & 10,46 & 6,69 & 22,88 & 11,71 & 11,49 & 11,39 & 17,47 & 28,74 & 25,49 \\
\hline $\mathrm{CVe}_{2}$ & 16,22 & 16,56 & 7,96 & 4,03 & - & 8,66 & 4,30 & 6,70 & 6,19 & 7,21 & 11,76 \\
\hline $\mathrm{CVg}_{\text {Ent }}$ & 8,88 & 9,05 & 13,77 & 7,37 & 27,30 & 11,43 & 4,61 & 7,05 & 19,43 & 26,88 & 59,85 \\
\hline $\mathrm{CVg} \mathrm{Entre} / \mathrm{CVe}_{2}$ & 0,55 & 0,55 & 1,73 & 1,83 & - & 1,32 & 1,07 & 1,05 & 3,14 & 3,73 & 5,09 \\
\hline $\mathrm{GS}_{\text {(Média) }}(\%)$ & $-12,29$ & $-12,69$ & $-22,52$ & $-11,21$ & $-64,32$ & $-21,78$ & 3,48 & 7,60 & $-34,78$ & 24,70 & $-96,80$ \\
\hline
\end{tabular}

*** significativo a 5\% e $1 \%$ de probabilidade pelo teste $\mathrm{F}$, respectivamente (significant at 5\% and 1\% probability by $\mathrm{F}$ test, respectively); $=$ estimativas inferiores a 0 (estimates below 0$) ; \mathrm{CRP}=$ comprimento da rama principal (main stem length); $\mathrm{TCRP}=$ taxa de crescimento da rama principal (main stem growth rate) $\mathrm{NDPFF}=$ dias para o florescimento da primeira flor feminina (days to flowering of the first female flower); NDPFM= dias para o florescimento da primeira flor masculina (days to flowering of the first male flower); NóPFM= localização do nó da primeira flor masculina (location of the first male flower node); $\mathrm{HC}=$ hábito de crescimento (growth habit); NR= número de ramas (number of branches); $\mathrm{NRG}=$ número de ramificações da gavinha (number of tendril branches); $\mathrm{SANID}=$ aspecto fitossanitário (phytosanitary aspect); $\mathrm{PROL}=$ prolificidade (prolificacy) e $\mathrm{MF}=$ massa do fruto (fruit mass).

de variação relativo inferiores a uma unidade. Valores do índice de variação superiores a uma unidade indicam a predominância dos efeitos genéticos sobre os ambientais (Azevedo et al., 2012), desta forma, há a possibilidade de se obterem ganhos genéticos com a seleção para a maioria das características (Cruz et al., 2012).

Para todas as características, verificou-se que as estimativas dos coeficientes de herdabilidade foram muito maiores para herdabilidade da média $\left(\mathrm{h}^{2}{ }_{\text {(média) }}\right)$ do que para as herdabilidades do indivíduo no bloco $\left(\mathrm{h}^{2}\right.$ (Indiv no bloco) $)$ e indivíduo no experimento ( $\mathrm{h}_{(\text {Indiv no exp) }}^{2}$ ). Assim, pode-se inferir que a seleção baseada na média dos acessos pode possibilitar maior sucesso para a seleção, resultados similares foram obtidos por Gonçalves et al. (2007), Costa et al. (2008), Farias Neto et al. (2008) e Azevedo et al. (2012).

O maior coeficiente de herdabilidade foi encontrado para a característica massa de frutos, concordando com os resultados de Bezerra Neto et al. (2006) que também encontraram alta herdabilidade para esta característica. As características número de dias para o florescimento da primeira flor feminina, número de dias para o florescimento da primeira flor masculina, localização do nó da primeira flor masculina e aspecto fitossanitário também apresentaram altas estimativas de herdabilidade, com valores superiores a 0,75 . A herdabilidade representa a confiabilidade com a qual o valor fenotípico representa o valor genotípico, consequentemente, características com alta herdabilidade refletem a menor influência do ambiente, o que aumenta o poder discriminatório dos mesmos (Ivoglo et al., 2008).

Os maiores ganhos esperados com a seleção foram encontrados para as características massa do fruto $(-96,80 \%)$ e localização do nó da primeira flor masculina (-64,32\%). Já nas características número de ramas e número de ramificações da gavinha foram observadas as menores estimativas de ganho esperado com a seleção $(3,48$ e $7,60 \%$, respectivamente), o que pode ser justificado pela menor variabilidade genética para estas características.

A maioria das estimativas de correlações genéticas foram superiores às correlações fenotípicas e ambientais (Tabela 2), indicando maior influência do componente genético em relação aos demais, resultado similar foi encontrado por Bezerra Neto et al. (2006) avaliando 
Tabela 2. Estimativas dos coeficientes de correlação fenotípica (rf), genotípica (rg) e de ambiente (re), entre 11 características em 55 acessos de abóbora do BGH-UFV e três cultivares comerciais \{estimates of phenotypic (rf), genotypic (rg) and environmental (re) correlation coefficients among 11 traits in 55 pumpkin accessions of BGH-UFV and three cultivars\}. Viçosa, UFV, 2011.

\begin{tabular}{|c|c|c|c|c|c|c|c|c|c|c|c|}
\hline Carac. & & TCRP & NDPFF & NDPFM & NóPFM & $\mathrm{HC}$ & NR & NRG & SANID & PROL & MF \\
\hline \multirow{3}{*}{ CRP } & $\mathrm{Rf}$ & 0,99 & 0,15 & 0,06 & 0,23 & 0,57 & 0,16 & 0,08 & $-0,27$ & 0,08 & 0,28 \\
\hline & $\mathrm{Rg}$ & 0,99 & 0,58 & 0,42 & 0,41 & 0,88 & $-0,25$ & 0,21 & $-0,41$ & $-0,06$ & 0,41 \\
\hline & $\mathrm{Re}$ & 0,99 & $-0,63$ & $-0,50$ & $-0,03$ & 0,21 & 0,41 & $-0,03$ & $-0,10$ & 0,28 & 0,13 \\
\hline \multirow{3}{*}{ TCRP } & $\mathrm{Rf}$ & & 0,16 & 0,06 & 0,23 & 0,57 & 0,16 & 0,08 & $-0,27$ & 0,08 & 0,27 \\
\hline & $\mathrm{Rg}$ & & 0,58 & 0,43 & 0,42 & 0,88 & $-0,26$ & 0,21 & $-0,41$ & $-0,06$ & 0,40 \\
\hline & $\mathrm{Re}$ & & $-0,63$ & $-0,49$ & $-0,03$ & 0,21 & 0,41 & $-0,03$ & $-0,11$ & 0,28 & 0,14 \\
\hline \multirow{3}{*}{ NDPFF } & $\mathrm{Rf}$ & & & 0,82 & 0,56 & 0,61 & 0,16 & 0,21 & $-0,74$ & $-0,21$ & 0,39 \\
\hline & $\mathrm{Rg}$ & & & 0,87 & 0,66 & 0,80 & 0,51 & 0,31 & $-0,88$ & $-0,20$ & 0,44 \\
\hline & $\operatorname{Re}$ & & & 0,58 & 0,08 & $-0,13$ & $-0,31$ & 0,01 & $-0,09$ & $-0,26$ & $-0,04$ \\
\hline \multirow{3}{*}{ NDPFM } & $\mathrm{Rf}$ & & & & 0,71 & 0,53 & $-0,06$ & 0,35 & $-0,54$ & $-0,10$ & 0,23 \\
\hline & $\mathrm{Rg}$ & & & & 0,77 & 0,72 & 0,12 & 0,55 & $-0,70$ & $-0,04$ & 0,28 \\
\hline & $\mathrm{Re}$ & & & & 0,50 & $-0,10$ & $-0,31$ & $-0,01$ & 0,04 & $-0,30$ & $-0,13$ \\
\hline \multirow{3}{*}{ NóPFM } & $\mathrm{Rf}$ & & & & & 0,59 & $-0,09$ & 0,19 & $-0,39$ & 0,08 & 0,20 \\
\hline & $\mathrm{Rg}$ & & & & & 0,76 & $-0,14$ & 0,31 & $-0,50$ & 0,14 & 0,22 \\
\hline & Re & & & & & 0,01 & $-0,06$ & $-0,04$ & 0,03 & $-0,14$ & 0,01 \\
\hline \multirow{3}{*}{$\mathrm{HC}$} & $\mathrm{Rf}$ & & & & & & 0,22 & 0,03 & $-0,64$ & 0,25 & 0,32 \\
\hline & $\mathrm{Rg}$ & & & & & & 0,37 & 0,03 & $-0,71$ & 0,17 & 0,35 \\
\hline & $\mathrm{Re}$ & & & & & & 0,10 & 0,04 & $-0,39$ & 0,47 & 0,22 \\
\hline \multirow{3}{*}{ NR } & $\mathrm{Rf}$ & & & & & & & $-0,36$ & $-0,09$ & 0,03 & 0,10 \\
\hline & $\mathrm{Rg}$ & & & & & & & $-0,91$ & $-0,07$ & $-0,03$ & 0,11 \\
\hline & $\mathrm{Re}$ & & & & & & & 0,02 & $-0,14$ & 0,09 & 0,22 \\
\hline \multirow{3}{*}{ NRG } & $\mathrm{Rf}$ & & & & & & & & $-0,19$ & $-0,22$ & 0,30 \\
\hline & $\mathrm{Rg}$ & & & & & & & & $-0,29$ & $-0,37$ & 0,43 \\
\hline & $\mathrm{Re}$ & & & & & & & & 0,00 & 0,03 & $-0,07$ \\
\hline \multirow{3}{*}{ SANID } & $\mathrm{Rf}$ & & & & & & & & & 0,11 & $-0,45$ \\
\hline & $\mathrm{Rg}$ & & & & & & & & & 0,23 & $-0,49$ \\
\hline & $\operatorname{Re}$ & & & & & & & & & $-0,28$ & $-0,24$ \\
\hline \multirow{3}{*}{ PROL } & $\mathrm{Rf}$ & & & & & & & & & & $-0,39$ \\
\hline & $\mathrm{Rg}$ & & & & & & & & & & $-0,48$ \\
\hline & $\operatorname{Re}$ & & & & & & & & & & 0,03 \\
\hline
\end{tabular}

$\mathrm{CRP}=$ comprimento da rama principal (main stem length); $\mathrm{TCRP}=$ taxa de crescimento da rama principal; (main stem growth rate), $\mathrm{NDPFF}=$ dias para o florescimento da primeira flor feminina (days to flowering of the first female flower); NDPFM= dias para o florescimento da primeira flor masculina (days to flowering of the first male flower); NóPFM=localização do nó da primeira flor masculina (location of the first male flower node); $\mathrm{HC}=$ hábito de crescimento (growth habit); $\mathrm{NR}=$ número de ramas (number of branches); $\mathrm{NRG}=$ número de ramificações da gavinha (number of tendril branches); $\mathrm{SANID}=$ aspecto fitossanitário (phytosanitary aspect); $\mathrm{PROL}=$ prolificidade (prolificacy) e MF= massa do fruto (fruit mass).

linhagens de abóbora. Foram encontradas altas estimativas de correlação entre as características comprimento da rama principal e taxa de crescimento da rama principal $(0,99)$, o que é esperado, em função da natureza das características. Altas estimativas de correlações genéticas foram encontradas entre o número de ramificações da gavinha e número de ramas $(0,91)$. O maior número de ramas em plantas de abóbora é indesejável, por dificultar o adensamento das plantas. Já o maior número de ramificações da gavinha é desejável, pois permite a maior fixação das ramas, e consequentemente, menores danos provocados pela ação antrópica ou dos ventos. O conhecimento da associação entre caracteres é importante no melhoramento de abóbora (Arauah et al., 2012) permitindo conhecer a consequência da seleção de uma característica nas demais (Cruz et al., 2012).

No melhoramento da cultura da abóbora a seleção para o hábito de crescimento arbustivo (introgressão do gene Bush) é desejável, pois possibi- 
Tabela 3. Agrupamentos formados pelo método de Tocher com base na distância generalizada de Mahalanobis e agrupamento de médias para características avaliadas em 55 acessos de abóbora do BGH-UFV e três cultivares comerciais (groups formed by the Tocher method based on the Mahalanobis distance and means clustering of characteristics evaluated in 55 pumpkin accessions of BGH-UFV and three cultivars). Viçosa, UFV, 2011.

\begin{tabular}{|c|c|c|c|c|c|c|c|c|c|c|c|c|}
\hline $\begin{array}{l}\text { Agrupamento } \\
\text { de Tocher } \\
\end{array}$ & Acesso & CRP & TCRP & NDPFF & NDPFM & NóPFM & $\mathrm{HC}$ & NR & NRG & SANID & PROL & MF \\
\hline 1. $\mathrm{I}^{1}$ & BGH-0672 & 2,92 & 10,25 & $41,07 \mathrm{c}$ & $40,40 \mathrm{c}$ & $4,53 \mathrm{c}$ & $3,78 \mathrm{a}$ & 5,00 & $3,11 \mathrm{~b}$ & $3,33 \mathrm{~b}$ & $5,67 \mathrm{c}$ & $4,53 \mathrm{~d}$ \\
\hline 1. I & BGH-0900 & 3,29 & 11,56 & $42,40 \mathrm{c}$ & $43,58 \mathrm{~b}$ & $5,73 \mathrm{~b}$ & $4,11 \mathrm{a}$ & 4,78 & $3,00 \mathrm{~b}$ & $3,44 \mathrm{~b}$ & $10,22 \mathrm{a}$ & $2,21 \mathrm{e}$ \\
\hline 1. I & BGH-1207 & 2,65 & 9,19 & $39,93 \mathrm{c}$ & $39,20 \mathrm{c}$ & $4,40 \mathrm{c}$ & $3,11 \mathrm{~b}$ & 5,44 & $3,22 \mathrm{~b}$ & $3,67 \mathrm{~b}$ & $6,22 \mathrm{~b}$ & $4,30 \mathrm{~d}$ \\
\hline 1. I & BGH-1219 & 2,64 & 9,23 & $50,47 \mathrm{~b}$ & $45,53 \mathrm{~b}$ & $9,47 \mathrm{a}$ & $4,33 \mathrm{a}$ & 5,34 & $3,22 \mathrm{~b}$ & $2,33 \mathrm{c}$ & $7,44 \mathrm{~b}$ & $4,05 \mathrm{~d}$ \\
\hline 1. I & BGH-1514 & 3,09 & 10,88 & $46,73 \mathrm{~b}$ & $42,42 \mathrm{c}$ & $4,38 \mathrm{c}$ & $3,78 \mathrm{a}$ & 5,78 & $3,22 \mathrm{~b}$ & $2,78 \mathrm{c}$ & $5,67 \mathrm{c}$ & $2,67 \mathrm{e}$ \\
\hline 1. I & BGH-1922 & 3,26 & 11,47 & $38,00 \mathrm{c}$ & $37,13 \mathrm{~d}$ & $3,40 \mathrm{c}$ & $3,78 \mathrm{a}$ & 5,33 & $3,11 \mathrm{~b}$ & $4,00 \mathrm{~b}$ & $6,56 \mathrm{~b}$ & $3,11 \mathrm{e}$ \\
\hline 1. I & BGH-1946 & 2,87 & 9,99 & $42,13 \mathrm{c}$ & $42,40 \mathrm{c}$ & $5,20 \mathrm{~b}$ & $4,00 \mathrm{a}$ & 4,89 & $3,22 \mathrm{~b}$ & $2,44 \mathrm{c}$ & $9,67 \mathrm{a}$ & $2,95 \mathrm{e}$ \\
\hline 1. I & BGH-1956 & 2,40 & 8,32 & $52,93 \mathrm{a}$ & $49,40 \mathrm{a}$ & $8,00 \mathrm{a}$ & $3,67 \mathrm{a}$ & 5,00 & $3,33 \mathrm{~b}$ & $3,11 \mathrm{c}$ & $7,56 \mathrm{~b}$ & $4,10 \mathrm{~d}$ \\
\hline 1. I & BGH-3333 & 2,85 & 10,00 & $43,78 \mathrm{c}$ & $44,27 \mathrm{~b}$ & $6,53 \mathrm{a}$ & $3,44 \mathrm{a}$ & 5,33 & $2,89 \mathrm{~b}$ & $3,89 \mathrm{~b}$ & $6,67 \mathrm{~b}$ & $2,69 \mathrm{e}$ \\
\hline 1. I & BGH-4139 & 2,58 & 9,09 & $47,87 \mathrm{~b}$ & $44,60 \mathrm{~b}$ & $7,33 \mathrm{a}$ & $3,89 \mathrm{a}$ & 5,00 & $3,11 \mathrm{~b}$ & $2,78 \mathrm{c}$ & $7,11 \mathrm{~b}$ & $4,41 \mathrm{~d}$ \\
\hline 1. I & BGH-4360 & 2,74 & 9,59 & $45,13 \mathrm{c}$ & $45,20 \mathrm{~b}$ & $6,47 \mathrm{a}$ & $3,72 \mathrm{a}$ & 4,83 & $3,78 \mathrm{a}$ & $3,56 \mathrm{~b}$ & $5,89 \mathrm{c}$ & $4,44 \mathrm{~d}$ \\
\hline 1. I & BGH-4514 & 3,15 & 11,00 & $46,53 \mathrm{~b}$ & $42,80 \mathrm{c}$ & $7,67 \mathrm{a}$ & $4,00 \mathrm{a}$ & 5,22 & $2,89 \mathrm{~b}$ & $4,11 \mathrm{a}$ & $6,44 \mathrm{~b}$ & $5,26 \mathrm{c}$ \\
\hline 1. I & BGH-4515 & 3,11 & 10,88 & $43,13 \mathrm{c}$ & $41,05 \mathrm{c}$ & $5,20 \mathrm{~b}$ & $4,00 \mathrm{a}$ & 5,11 & $3,11 \mathrm{~b}$ & $3,00 \mathrm{c}$ & $6,89 \mathrm{~b}$ & $4,89 \mathrm{~d}$ \\
\hline 1. I & BGH-4585 & 2,95 & 10,33 & $39,47 \mathrm{c}$ & $41,80 \mathrm{c}$ & $5,20 \mathrm{~b}$ & $3,78 \mathrm{a}$ & 5,22 & $3,00 \mathrm{~b}$ & $3,56 \mathrm{~b}$ & $7,00 \mathrm{~b}$ & $3,14 \mathrm{e}$ \\
\hline 1. I & BGH-4586 & 2,86 & 10,06 & $43,20 \mathrm{c}$ & $44,53 \mathrm{~b}$ & 8,13 a & $4,00 \mathrm{a}$ & 5,33 & $3,45 \mathrm{a}$ & $2,56 \mathrm{c}$ & $7,44 \mathrm{~b}$ & $4,30 \mathrm{~d}$ \\
\hline 1. I & BGH-4600 & 2,83 & 9,93 & $41,80 \mathrm{c}$ & $44,40 \mathrm{~b}$ & $7,00 \mathrm{a}$ & $4,00 \mathrm{a}$ & 5,11 & $3,22 \mathrm{~b}$ & $3,33 \mathrm{~b}$ & $8,78 \mathrm{a}$ & $3,56 \mathrm{e}$ \\
\hline 1. I & BGH-4615 & 2,57 & 9,00 & $41,93 \mathrm{c}$ & $41,88 \mathrm{c}$ & $6,70 \mathrm{a}$ & $3,33 \mathrm{~b}$ & 5,11 & $3,22 \mathrm{~b}$ & $3,89 \mathrm{~b}$ & $9,11 \mathrm{a}$ & $2,32 \mathrm{e}$ \\
\hline 1. I & BGH-4617 & 2,80 & 9,81 & $43,53 \mathrm{c}$ & $44,07 \mathrm{~b}$ & $4,40 \mathrm{c}$ & $3,67 \mathrm{a}$ & 5,11 & $3,55 \mathrm{a}$ & $3,78 \mathrm{~b}$ & $10,11 \mathrm{a}$ & $3,16 \mathrm{e}$ \\
\hline 1. I & BGH-4623 & 2,72 & 9,51 & $40,27 \mathrm{c}$ & $40,73 \mathrm{c}$ & $3,53 \mathrm{c}$ & $3,22 \mathrm{~b}$ & 5,33 & $3,11 \mathrm{~b}$ & $3,00 \mathrm{c}$ & $6,14 \mathrm{~b}$ & $2,52 \mathrm{e}$ \\
\hline 1. I & BGH-4628 & 2,19 & 7,67 & $46,33 \mathrm{~b}$ & $47,30 \mathrm{a}$ & $7,28 \mathrm{a}$ & $3,89 \mathrm{a}$ & 5,22 & $3,00 \mathrm{~b}$ & $3,67 \mathrm{~b}$ & $6,56 \mathrm{~b}$ & $3,23 \mathrm{e}$ \\
\hline 1. I & BGH-5210 & 3,37 & 11,79 & $47,80 \mathrm{~b}$ & $44,27 \mathrm{~b}$ & $5,67 \mathrm{~b}$ & $3,56 \mathrm{a}$ & 5,33 & $3,44 \mathrm{a}$ & $2,67 \mathrm{c}$ & $5,67 \mathrm{c}$ & $6,11 \mathrm{c}$ \\
\hline 1. I & BGH-5232 & 2,97 & 10,45 & $38,47 \mathrm{c}$ & $41,53 \mathrm{c}$ & $5,93 \mathrm{~b}$ & 3,67 a & 5,33 & $3,22 \mathrm{~b}$ & $2,89 \mathrm{c}$ & 8,67 a & $4,33 \mathrm{~d}$ \\
\hline 1. I & BGH-5233 & 2,93 & 10,23 & $52,27 \mathrm{a}$ & $47,25 \mathrm{a}$ & $8,75 \mathrm{a}$ & $4,22 \mathrm{a}$ & 5,56 & $3,78 \mathrm{a}$ & $2,89 \mathrm{c}$ & $5,67 \mathrm{c}$ & $4,81 \mathrm{~d}$ \\
\hline 1. I & BGH-5235 & 2,92 & 10,25 & $42,87 \mathrm{c}$ & $44,93 \mathrm{~b}$ & $8,33 \mathrm{a}$ & $4,11 \mathrm{a}$ & 5,11 & $3,33 \mathrm{~b}$ & $4,00 \mathrm{~b}$ & $6,78 \mathrm{~b}$ & $4,44 \mathrm{~d}$ \\
\hline 1. I & BGH-5253 & 2,56 & 8,94 & $42,42 \mathrm{c}$ & $41,53 \mathrm{c}$ & $6,13 \mathrm{~b}$ & $3,00 \mathrm{~b}$ & 4,22 & $3,33 \mathrm{~b}$ & $4,22 \mathrm{a}$ & $7,22 \mathrm{~b}$ & $2,41 \mathrm{e}$ \\
\hline 1. I & BGH-5257 & 2,53 & 8,90 & $47,20 \mathrm{~b}$ & $48,27 \mathrm{a}$ & $7,78 \mathrm{a}$ & $3,78 \mathrm{a}$ & 5,22 & $3,00 \mathrm{~b}$ & $3,89 \mathrm{~b}$ & $9,33 \mathrm{a}$ & $2,66 \mathrm{e}$ \\
\hline 1. I & BGH-5449 & 2,97 & 10,43 & $46,73 \mathrm{~b}$ & $44,60 \mathrm{~b}$ & $7,87 \mathrm{a}$ & $3,56 \mathrm{a}$ & 5,00 & $3,00 \mathrm{~b}$ & $3,33 \mathrm{~b}$ & $6,11 \mathrm{~b}$ & $4,04 \mathrm{~d}$ \\
\hline 1. I & BGH-5622 & 2,58 & 9,10 & $44,70 \mathrm{c}$ & $43,80 \mathrm{~b}$ & $5,00 \mathrm{~b}$ & $3,78 \mathrm{a}$ & 4,78 & $3,56 \mathrm{a}$ & $3,11 \mathrm{c}$ & $5,78 \mathrm{c}$ & $3,90 \mathrm{~d}$ \\
\hline 1. I & BGH-6996 & 2,87 & 10,12 & $43,13 \mathrm{c}$ & $42,60 \mathrm{c}$ & $4,87 \mathrm{~b}$ & $3,89 \mathrm{a}$ & 4,67 & $2,89 \mathrm{~b}$ & $3,22 \mathrm{c}$ & $5,33 \mathrm{c}$ & $2,51 \mathrm{e}$ \\
\hline 1. I & BGH-6997 & 2,58 & 9,07 & $51,20 \mathrm{~b}$ & $51,07 \mathrm{a}$ & $7,40 \mathrm{a}$ & $3,56 \mathrm{a}$ & 5,11 & $3,67 \mathrm{a}$ & $3,22 \mathrm{c}$ & $4,89 \mathrm{c}$ & $3,26 \mathrm{e}$ \\
\hline 1. I & BGH-7319 & 2,73 & 9,56 & $55,37 \mathrm{a}$ & 50,53 a & $7,93 \mathrm{a}$ & $3,89 \mathrm{a}$ & 5,11 & $3,22 \mathrm{~b}$ & $2,67 \mathrm{c}$ & $4,11 \mathrm{c}$ & $4,32 \mathrm{~d}$ \\
\hline 1. I & BGH-7660 & 3,48 & 12,24 & $39,47 \mathrm{c}$ & $39,60 \mathrm{c}$ & $2,27 \mathrm{c}$ & 3,44 a & 5,22 & $3,33 \mathrm{~b}$ & $3,56 \mathrm{~b}$ & $6,56 \mathrm{~b}$ & $4,48 \mathrm{~d}$ \\
\hline 1. I & BGH-7661 & 2,36 & 8,18 & $41,00 \mathrm{c}$ & $41,47 \mathrm{c}$ & $5,87 \mathrm{~b}$ & $3,56 \mathrm{a}$ & 5,00 & $2,89 \mathrm{~b}$ & $3,67 \mathrm{~b}$ & $6,78 \mathrm{~b}$ & $3,29 \mathrm{e}$ \\
\hline 1. I & BGH-7662 & 2,83 & 9,95 & $41,33 \mathrm{c}$ & $40,67 \mathrm{c}$ & $4,20 \mathrm{c}$ & $3,56 \mathrm{a}$ & 5,67 & $3,22 \mathrm{~b}$ & $3,78 \mathrm{~b}$ & $6,89 \mathrm{~b}$ & $5,50 \mathrm{c}$ \\
\hline 1. I & BGH-7663 & 2,62 & 9,16 & $40,13 \mathrm{c}$ & $40,47 \mathrm{c}$ & $4,73 \mathrm{~b}$ & $3,11 \mathrm{~b}$ & 4,89 & $3,45 \mathrm{a}$ & 4,56 a & $4,44 \mathrm{c}$ & $3,73 \mathrm{e}$ \\
\hline 1. I & BGH-7664 & 2,79 & 9,81 & $44,28 \mathrm{c}$ & $45,60 \mathrm{~b}$ & $9,13 \mathrm{a}$ & $3,67 \mathrm{a}$ & 4,78 & $3,33 \mathrm{~b}$ & $3,22 \mathrm{c}$ & $4,89 \mathrm{c}$ & $4,55 \mathrm{~d}$ \\
\hline 1. I & BGH-7667 & 2,73 & 9,54 & $49,80 \mathrm{~b}$ & $44,73 \mathrm{~b}$ & $6,20 \mathrm{~b}$ & $4,11 \mathrm{a}$ & 5,67 & $3,67 \mathrm{a}$ & $3,44 \mathrm{~b}$ & $8,67 \mathrm{a}$ & $5,82 \mathrm{c}$ \\
\hline 1. I & BGH-7764 & 3,06 & 10,68 & $43,27 \mathrm{c}$ & $44,52 \mathrm{~b}$ & 8,48 a & $4,11 \mathrm{a}$ & 5,78 & $3,00 \mathrm{~b}$ & $3,33 \mathrm{~b}$ & $6,56 \mathrm{~b}$ & $4,84 \mathrm{~d}$ \\
\hline 1. I & BGH-7766 & 3,20 & 11,19 & $42,53 \mathrm{c}$ & $43,60 \mathrm{~b}$ & $7,07 \mathrm{a}$ & $4,33 \mathrm{a}$ & 5,33 & $3,22 \mathrm{~b}$ & $3,33 \mathrm{~b}$ & $7,00 \mathrm{~b}$ & $3,45 \mathrm{e}$ \\
\hline
\end{tabular}

Continua ... 
Tabela 3. Continuação ...

\begin{tabular}{|c|c|c|c|c|c|c|c|c|c|c|c|c|}
\hline $\begin{array}{l}\text { Agrupamento } \\
\text { de Tocher }\end{array}$ & Acesso & CRP & TCRP & NDPFF & NDPFM & NóPFM & HC & NR & NRG & SANID & PROL & MF \\
\hline 1. I & Jacarezinho & 2,61 & 9,17 & $46,87 \mathrm{~b}$ & $41,67 \mathrm{c}$ & $4,80 \mathrm{~b}$ & $3,67 \mathrm{a}$ & 4,89 & $3,22 \mathrm{~b}$ & $3,11 \mathrm{c}$ & $5,33 \mathrm{c}$ & $2,78 \mathrm{e}$ \\
\hline 1. II & BGH-7003 & 2,10 & 7,30 & $25,47 \mathrm{~d}$ & $35,60 \mathrm{~d}$ & $3,73 \mathrm{c}$ & $2,00 \mathrm{c}$ & 4,78 & $3,22 \mathrm{~b}$ & $5,00 \mathrm{a}$ & $3,56 \mathrm{c}$ & $1,16 \mathrm{e}$ \\
\hline 1. II & Butternut & 2,24 & 7,82 & $26,13 \mathrm{~d}$ & $35,27 \mathrm{~d}$ & $3,53 \mathrm{c}$ & $2,00 \mathrm{c}$ & 4,33 & $3,56 \mathrm{a}$ & $5,00 \mathrm{a}$ & $3,22 \mathrm{c}$ & $1,27 \mathrm{e}$ \\
\hline 1. III & BGH-7316 & 3,08 & 10,86 & 56,35 a & 48,43 a & $8,00 \mathrm{a}$ & $3,89 \mathrm{a}$ & 4,67 & $3,67 \mathrm{a}$ & $1,67 \mathrm{c}$ & $4,33 \mathrm{c}$ & $6,26 \mathrm{c}$ \\
\hline 1. III & BGH-7317 & 3,58 & 12,63 & 55,47 a & $49,20 \mathrm{a}$ & $8,72 \mathrm{a}$ & $4,67 \mathrm{a}$ & 5,44 & $3,56 \mathrm{a}$ & $2,22 \mathrm{c}$ & $6,22 \mathrm{~b}$ & $5,05 \mathrm{~d}$ \\
\hline 1. III & BGH-7318 & 1,94 & 6,77 & 56,00 a & $47,38 \mathrm{a}$ & $7,05 \mathrm{a}$ & $3,78 \mathrm{a}$ & 5,00 & $3,89 \mathrm{a}$ & $2,89 \mathrm{c}$ & $7,72 \mathrm{~b}$ & $3,05 \mathrm{e}$ \\
\hline 1. III & BGH-7671 & 3,32 & 11,69 & $60,53 \mathrm{a}$ & $51,40 \mathrm{a}$ & $10,47 \mathrm{a}$ & $4,22 \mathrm{a}$ & 5,45 & $3,44 \mathrm{a}$ & $2,56 \mathrm{c}$ & $2,22 \mathrm{c}$ & $5,95 \mathrm{c}$ \\
\hline 1.III & BGH-6999 & 2,90 & 10,14 & $51,00 \mathrm{~b}$ & $45,87 \mathrm{~b}$ & $6,07 \mathrm{~b}$ & $4,45 \mathrm{a}$ & 4,89 & $3,33 \mathrm{~b}$ & $2,56 \mathrm{c}$ & $4,11 \mathrm{c}$ & $4,39 \mathrm{~d}$ \\
\hline 1.III & BGH-7665 & 2,97 & 10,45 & 59,48 a & $46,00 \mathrm{~b}$ & $5,73 \mathrm{~b}$ & $3,89 \mathrm{a}$ & 5,67 & $3,44 \mathrm{a}$ & $2,44 \mathrm{c}$ & $3,11 \mathrm{c}$ & $4,48 \mathrm{~d}$ \\
\hline 1.IV & BGH-6153 & 3,40 & 12,03 & $52,72 \mathrm{a}$ & $44,20 \mathrm{~b}$ & $5,95 \mathrm{~b}$ & $4,33 \mathrm{a}$ & 5,33 & $3,33 \mathrm{~b}$ & $2,11 \mathrm{c}$ & $4,67 \mathrm{c}$ & $11,51 \mathrm{~b}$ \\
\hline 1. IV & BGH-6154 & 3,05 & 10,77 & 53,40 a & $46,47 \mathrm{~b}$ & $8,53 \mathrm{a}$ & $3,89 \mathrm{a}$ & 4,67 & $4,00 \mathrm{a}$ & $2,33 \mathrm{c}$ & $4,11 \mathrm{c}$ & $10,01 \mathrm{~b}$ \\
\hline 1. $\mathrm{V}$ & BGH-5621 & 2,13 & 7,40 & $39,73 \mathrm{c}$ & $41,77 \mathrm{c}$ & $3,12 \mathrm{c}$ & $3,11 \mathrm{~b}$ & 5,67 & $3,22 \mathrm{~b}$ & $3,44 \mathrm{~b}$ & $7,56 \mathrm{~b}$ & $2,10 \mathrm{e}$ \\
\hline 1. V & BGH-0035 & 1,41 & 4,82 & $47,87 \mathrm{~b}$ & $45,87 \mathrm{~b}$ & $3,40 \mathrm{c}$ & $2,94 \mathrm{~b}$ & 4,72 & $3,22 \mathrm{~b}$ & $3,00 \mathrm{c}$ & $3,44 \mathrm{c}$ & $3,20 \mathrm{e}$ \\
\hline 1. VI & BGH-5635 & 2,51 & 8,77 & $55,67 \mathrm{a}$ & 50,40 a & $5,67 \mathrm{~b}$ & $3,33 \mathrm{~b}$ & 5,33 & $3,11 \mathrm{~b}$ & $3,44 \mathrm{~b}$ & $3,00 \mathrm{c}$ & $6,28 \mathrm{c}$ \\
\hline 1. VI & BGH-7666 & 2,36 & 8,20 & $49,27 \mathrm{~b}$ & $47,22 \mathrm{a}$ & $5,75 \mathrm{~b}$ & $3,56 \mathrm{a}$ & 4,89 & $3,56 \mathrm{a}$ & $2,33 \mathrm{c}$ & $4,00 \mathrm{c}$ & $6,30 \mathrm{c}$ \\
\hline 1.VII & BGH-3581 & 2,57 & 9,04 & $38,00 \mathrm{c}$ & $39,12 \mathrm{c}$ & $4,33 \mathrm{c}$ & $3,44 \mathrm{a}$ & 6,33 & $2,78 \mathrm{~b}$ & $4,44 \mathrm{a}$ & $5,11 \mathrm{c}$ & $3,79 \mathrm{e}$ \\
\hline 1. VIII & Tetsukabuto & 3,24 & 11,37 & $36,73 \mathrm{c}$ & 49,17 a & 7,65 a & $3,67 \mathrm{a}$ & 3,89 & $4,55 \mathrm{a}$ & $4,22 \mathrm{a}$ & $6,56 \mathrm{~b}$ & $2,49 \mathrm{e}$ \\
\hline 1. IX & BGH-7765 & 2,79 & 9,74 & $50,08 \mathrm{~b}$ & $46,60 \mathrm{~b}$ & $10,20 \mathrm{a}$ & $4,44 \mathrm{a}$ & 4,45 & $3,00 \mathrm{~b}$ & $2,44 \mathrm{c}$ & $10,00 \mathrm{a}$ & $2,92 \mathrm{e}$ \\
\hline 2 & BGH-7673 & 2,88 & 10,02 & $48,67 \mathrm{~b}$ & $44,73 \mathrm{~b}$ & $6,53 \mathrm{a}$ & $4,00 \mathrm{a}$ & 5,00 & $3,78 \mathrm{a}$ & $2,44 \mathrm{c}$ & $2,44 \mathrm{c}$ & $20,23 \mathrm{a}$ \\
\hline
\end{tabular}

${ }^{1}$ Números arábicos e romanos indicam os grupos e subgrupos formados pelo método Tocher, respectivamente (Arabic and Roman numbers indicate the groups and sub groups formed by Tocher method, respectively); Grupos de médias seguidas pela mesma letra nas colunas não diferem significativamente entre si, pelo teste de Scott-Knott, a 5\% de probabilidade (groups of means followed by the same letter in the columns do not differ significantly, $\mathrm{Scott}-\mathrm{Knott}$ test, $5 \%$ probability); $\mathrm{CRP}=$ comprimento da rama principal (main stem length); $\mathrm{TCRP}=$ taxa de crescimento da rama principal (main stem growth rate); NDPFF= dias para o florescimento da primeira flor feminina (days to flowering of the first female flower); NDPFM= dias para o florescimento da primeira flor masculina (days to flowering of the first male flower); NóPFM= localização do nó da primeira flor masculina (location of the first male flower node); HC= hábito de crescimento (growth habit); $\mathrm{NR}=$ número de ramas (number of branches); $\mathrm{NRG}=$ número de ramificações da gavinha (number of tendril branches); $\mathrm{SANID}=$ aspecto fitossanitário (phytosanitary aspect); $\mathrm{PROL}=$ prolificidade (prolificacy) e $\mathrm{MF}=$ massa do fruto (fruit mass).

lita o maior adensamento das plantas (Latif et al., 2012). Pelas estimativas de correlação $\left(r_{f}\right.$ e $\left.r_{g}\right)$ verifica-se que a consequência desta seleção pode ser a redução do número de dias para o florescimento da primeira flor feminina, do número de dias para o florescimento da primeira flor masculina, da localização do nó da primeira flor masculina, do número de ramas e uma piora quanto ao aspecto fitossanitário. A redução do número de dias para o florescimento da primeira flor feminina e masculina é desejável, pois aumenta a precocidade de frutificação da planta. As estimativas negativas de correlação $\left(r_{f}\right.$ e $\left.r_{g}\right)$ entre o aspecto fitossanitário com o comprimento da rama principal, taxa de crescimento da rama principal e hábito de crescimento indicam que plantas mais compactas podem ter maiores problemas fitossanitários.

Baixas estimativas de correlação foram encontradas entre o número de frutos por plantas e as demais características (Tabela 2), indicando que a seleção para esta característica não traria grande consequência nas demais; o mesmo foi observado para a massa de fruto. De forma geral, foram observadas baixas estimativas para os coeficientes de correlação residual $\left(\mathrm{r}_{\mathrm{e}}\right)$; segundo Cruz et al. (2012), estas estimativas são altas quando dois caracteres são influenciados pelas mesmas diferenças de condições ambientais.

Embora se tenha verificado significância ao nível de $5 \%$ de probabilidade pelo teste $\mathrm{F}$ quanto ao efeito dos genótipos para as características comprimento da rama principal, taxa de crescimento da rama principal e número de ramas, as médias não se diferiram pelo teste Scott-Knott. A cultivar Butternut e o acesso BGH-7003 tiveram o menor número de dias para o florescimento da primeira flor masculina e feminina simultaneamente, sendo estes os genótipos mais precoces quanto ao florescimento.

A cultivar Butternut e os acessos BGH-0035, BGH-0672, BGH-1207, BGH-1514, BGH-1922, BGH-3581, BGH-4617, BGH-4623, BGH-5621, BGH-7003, BGH-7660 e BGH-7662 tiveram menores médias para a localização do nó da primeira flor masculina, significando maior precocidade. Para 


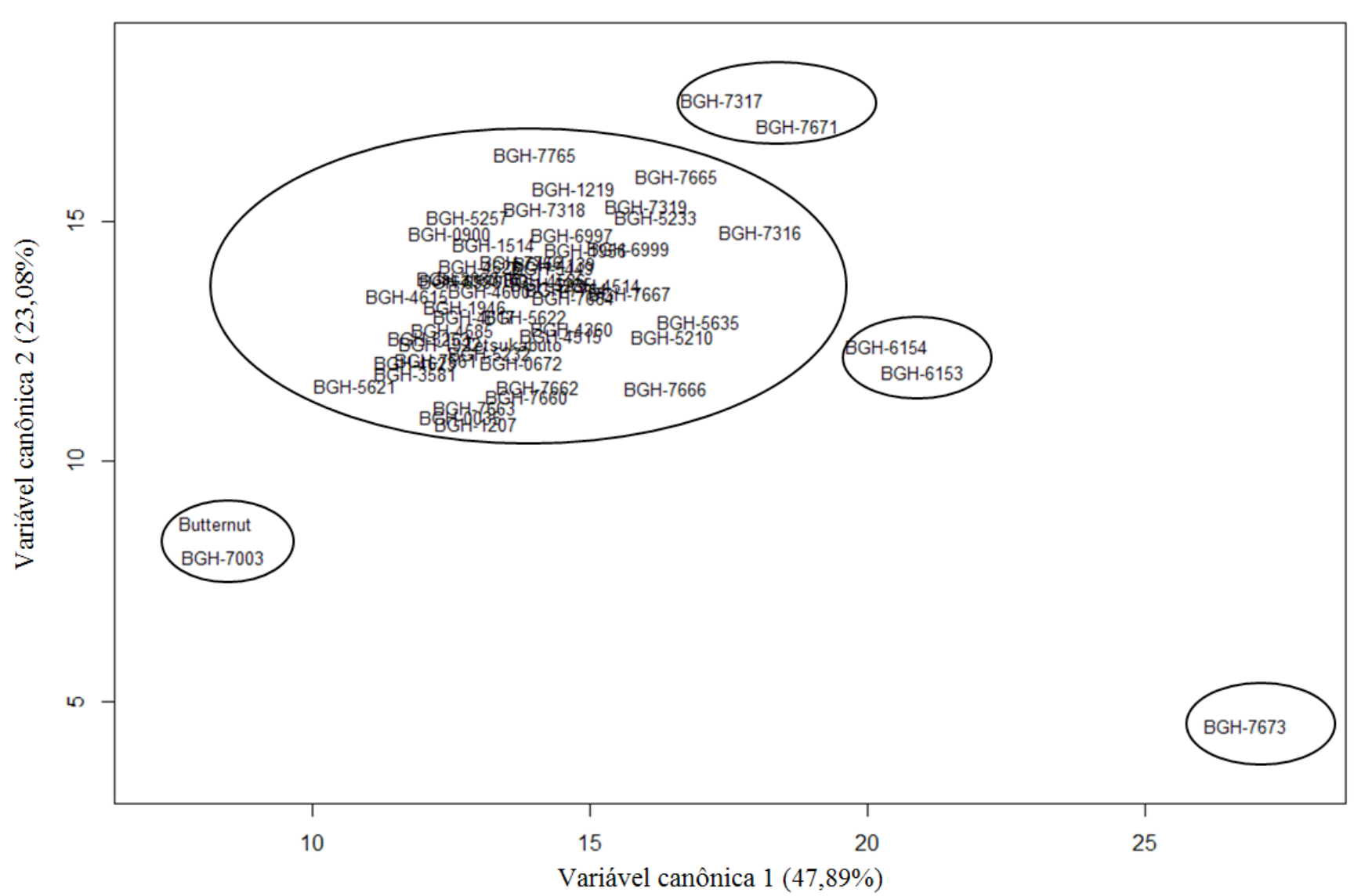

Figura 1. Dispersão gráfica dos escores em relação às duas primeiras variáveis canônicas de 55 acessos de abóbora do BGH-UFV e três cultivares comerciais (graphic dispersion of scores in relation to the first two canonical variables of 55 pumpkin accessions of BGH-UFV and three cultivars). Viçosa, UFV, 2011.

o hábito de crescimento, a cultivar comercial Butternut e o acesso BGH7003 obtiveram as menores notas, sendo possíveis fontes de genes para o hábito de crescimento determinado, permitindo maior adensamento de plantas e produtividade de frutos. Observou-se também que a maioria dos acessos é de hábito de crescimento indeterminado, com médias acima de 3. Para o número de ramificações da gavinha encontraram-se maiores valores para as cultivares comerciais Butternut, Tetsukabuto e os acessos BGH-4360, BGH-4586, BGH-4617, BGH-5210, BGH-5233, BGH-5622, BGH-6154, BGH-6997, BGH-7316, BGH-7317, BGH-7318, BGH-7663, BGH-7665, BGH-7666, BGH-7667, BGH-7671 e BGH-7673.

As cultivares comerciais Butternut e Tetsukabuto foram alocadas no grupo dos genótipos com maiores notas para o aspecto fitossanitário, indicando elevada suscetibilidade e a necessidade do melhoramento genético para esta característica. Em cucurbitáceas, uma de suas principais doenças, o oídio (Podosphaera xanthii) pode ser controlado com o uso de fungicida específico, porém a utilização de cultivares resistentes é uma alternativa interessante para a cultura (Boiteux et. al., 1995; Zitter et al., 1996: Nakada-Freitas et al., 2014).

Maiores números de frutos por planta foram encontrados para os acessos BGH-0900, BGH-1946, BGH-4600, BGH-4615, BGH-4617, BGH-5232, BGH-5257, BGH-7667 e BGH-7765 (Tabela 3); já as cultivares comerciais Butternut, Caserta e Jacarezinho foram alocadas no grupo dos genótipos com menor número de frutos por planta. Os acessos BGH-0035, BGH-0900, BGH-1514, BGH-1922, BGH-1946, BGH-3333, BGH-3581, BGH-4585, BGH-4600, BGH-4615, BGH-4617, BGH-4623, BGH-4628, BGH-5253, BGH-5257, BGH-5621, BGH-6996, BGH-6997, BGH-7003, BGH-7318, BGH-7661, BGH-7663, BGH-7765,
BGH-7766 e as cultivares comerciais Butternut, Jacarezinho e Tetsukabuto apresentaram menores médias de massa de fruto, com valores variando de 1,16 a $3,79 \mathrm{~kg}$. Espitia et al. (2006), avaliando 15 genótipos de abóbora, encontraram média de 3,9 kg de massa de fruto, já Restrepo et al. (2014) encontraram média de $3,37 \mathrm{~kg}$ avaliando 281 acessos de Cucurbita moschata. No Brasil prevalece o consumo de abóboras com massa fresca de até $3 \mathrm{~kg}$ (Resende et $a l ., 2013)$. Esses resultados indicam que essa variável é importante em programas de melhoramento, principalmente se há preferência em selecionar genitores que produzam frutos com peso requerido pelo mercado (frutos pequenos).

Além do desempenho per se, para a seleção de melhores genitores para programas de melhoramento é importante que se conheça a dissimilaridade genética entre os genótipos (Bertan et al., 2006). Desta forma, pode-se observar na tabela 3 que o acesso mais 
divergente foi $\mathrm{BGH}-7673$, formando um grupo à parte dos demais (Tabela 3 ). Fazendo um sub-agrupamento mediante método de Tocher, considerando apenas os acessos pertencentes ao Grupo 1 (grupo formado por 57 genótipos), foi obtida a formação de 9 subgrupos, quando os genótipos BGH-3581, Tetsukabuto e BGH-7765 formaram três subgrupos, distinguindo-se dos demais. Balkaya et al. (2010) também encontraram dissimilaridade genética ao avaliar descritores agromorfológicos em 115 populações de abóboras.

Para a melhor visualização da dissimilaridade existente entre os genótipos, foi apresentada a dispersão gráfica dos escores em relação às duas primeiras variáveis canônicas (Figura 1). Segundo esta técnica, pode-se considerar a formação de cinco grupos, verificando-se que o acesso BGH-7673 é o mais dissimilar em relação aos demais. A principal característica deste acesso que o distingue dos demais é a maior massa de frutos. Outros quatro grupos foram formados, o primeiro pelos acessos BGH-6153 e BGH-6154, o segundo pelos acessos BGH-7317 e BGH-7671, o terceiro pelo acesso BGH-7003 e a cultivar Butternut e o quarto grupo pelos demais acessos e o híbrido Tetsukabuto. Logo, o cruzamento do acesso BGH-7003 ou da cultivar Butternut com os acessos BGH-1946 ou BGH-7765 podem gerar progênies com potencial para o melhoramento genético, pois o acesso BGH-7003 e a cultivar Butternut, além de serem dissimilares em relação aos demais (Figura 1), possuem características favoráveis como hábito de crescimento mais compacto e menor matéria fresca de fruto, embora possuam baixa prolificidade e problemas fitossanitários (Tabela 3). Já os acessos BGH-1946 e BGH-7765 apresentam melhores notas quanto ao aspecto fitossanitário, maior prolificidade e baixa massa fresca por fruto (Tabela 3), embora tenham hábito de crescimento mais prostrado.

Portanto, houve variabilidade genética entre os acessos, com predominância dos efeitos genéticos sobre os ambientais. São esperados maiores ganhos de seleção para a massa por fruto, aspecto fitossanitário e localização do nó da primeira flor masculina. As cultivares comerciais Butternut e Tetsukabuto se destacaram em função da menor massa por fruto e maior precocidade de florescimento, porém têm resultados indesejáveis quanto ao aspecto fitossanitário. As estimativas negativas de correlação entre o aspecto fitossanitário com o hábito de crescimento, comprimento e taxa de crescimento da rama principal indicam que plantas compactas podem ter maiores problemas fitossanitários. O cruzamento do acesso BGH-7003 ou da cultivar Butternut com os acessos BGH-1946 ou BGH-7765 podem gerar progênies com potencial para o melhoramento genético.

\section{AGRADECIMENTOS}

Ao CNPq, FAPEMIG e CAPES pela concessão de bolsas de estudos e recursos financeiros para o desenvolvimento do projeto.

\section{REFERÊNCIAS}

AGRIANUAL. 2015. Anuário da agricultura brasileira. São Paulo, FNP-Consultoria e Agroinformativo, 516p.

ARUAH, BC; UGURU, MI; OYIGA, BC. 2012. Genetic variability and inter-relatioship among some Nigerian pumpkin accessions (Cucurbita spp.). International Journal of Plant Breeding 6: 34-41.

AZEVEDO, AM; ANDRADE JÚNIOR, VC; PEDROSA, CE; FERNANDES, JSC; VALADARES, NR; FERREIRA, MRA; MARTINS, RAV. 2012. Desempenho agronômico e variabilidade genética em genótipos de couve. Pesquisa Agropecuária Brasileira 47: 1751-1758.

BALKAYA, A; ÖZBAKIR, M; KURTA, ES 2010. The phenotypic diversity and fruit characterization of winter squash (Cucurbita maxima) populations from the Black Sea Region of Turkey. African Jornal of Biotechnology 9: 152-162.

BERTAN, I; CARVALHO, FIF; OLIVEIRA, AC; SILVA, JAG; BENIN, G; VIEIRA, EA; SILVA, GO; HARTWIG, I; VALÉRIO, IP; FINATTO, T. 2006.Dissimilaridade genética entre genótipos de trigo avaliados em cultivo hidropônico sob estresse por alumínio. Bragantia 65: 55-63.

BEZERRA NETO, FV; LEAL, NR; COSTA, FR; GONÇALVES, GM; AMARAL JÚNIOR, AT; VASCONCELLOS, HO; MIGUEL, MELLO M. 2006. Análise biométrica de linhagens de abóbora. Horticultura brasileira 24: 378-380.

BLANK, AF; SILVA, TB; MATOS, ML; CARVALHO FILHO, JLS; SILVA-MANN, R. 2013. Parâmetros genotípicos, fenotípicos e ambientais para caracteres morfológicos e agronômicos em abóbora. Horticultura Brasileira 31: 106-111.

BOITEUX, LS; REIFSCHNEIDER, FJB; PESSOA, HBV.1995. Phenotypic expression of quantitative and qualitative components of partial resistance to powdery mildew (Sphaerotheca fuliginearace) in melon (Cucumis melo) germplasm. Plant Breeding 114: 185-187.

BORGES, RME; RESENDE, GM; LIMA, MAC; DIAS, RCS; LUBARINO, PCC; OLIVEIRA, RCS; GONÇALVES, NPS. 2011. Phenotypic variability among pumpkin accessions in the Brazilian Semiarid. Horticultura Brasileira 29: 461-464.

COSTA, RB; RESENDE, MV; GONÇALVES, PS; CHICHORRO, JF; RODRIGUES, ROA. 2008. Variabilidade genética e seleção para caracteres de crescimento da seringueira. Bragantia 67: 299-305.

CRUZ, CD. 2013. GENES - a software package for analysis in experimental statistics and quantitative genetics. Acta Scientiarum 5: 271-276.

CRUZ, CD; REGAZZI, AJ; CARNEIRO, PCS. 2012. Modelos biométricos aplicados ao melhoramento genético. Viçosa: UFV. 514p.

ESQUINAS-ALCAZAR, JT; GULICK, PJ. 1983. Genetic resources of Cucurbitaceae. Rome: IBPGR (International Board for Plant Genetic Resouces). p. 1-7.

FARIAS NETO, JT; RESENDE, MDVD; OLIVEIRA, MSP; NOGUEIRA, OL; FALCÃO, PNB; SANTOS, NSA. 2008. Estimativas de parâmetros genéticos e ganhos de seleção em progênies de polinização aberta de açaizeiro. Revista Brasileira de Fruticultura 30: 1051-1056.

FILGUEIRA, FAR. 2007. Novo manual de olericultura: agrotecnologia moderna na produção e comercialização de hortaliças. 3.ed. Viçosa: UFV. 421p.

FREITAS, RG; VASCONCELOS, ES; CRUZ, CD; ROSADO, AM; ROCHA, RB; TAKAMI, LK. 2009. Predição de ganhos genéticos em progênies de polinização aberta de Eucalyptus urograndis cultivadas em diferentes ambientes e submetidas a diferentes procedimentos de seleção. Revista Árvore 33: 255-263.

GONÇALVES, GM; VIANA, AP; BEZERRA NETO, FV; PEREIRA, MG; PEREIRA, TNS. 2007. Seleção e herdabilidade na predição de ganhos genéticos em maracujá-amarelo. Pesquisa Agropecuária Brasileira 42: 193198.

IVOGLO, MG; FAZUOLI, LC; OLIVEIRA, ACB; GALLO, PB; MISTRO, JC; SILVAROLLA, MB; TOMA-BRAGHINI, M. 2008. Divergência genética entre progênies de café robusta. Bragantia 67: 823-83.

L A T I F, I M ; B A R I M AVA N D, I A ; SEDAGHATHOOR, S; LIPAYI, SR.2012. Sowing date and plant population effects on seed yield of Cucurbita pepo. International Journal Agriculture Biology 14: 641-644.

NAKADA-FREITAS, PG; SANDRI, MA; CARDOSO, AI; EBERHARDT NETO, E. 2014. Controle alternativo de oídio em abobrinha de moita com solução de vinagre. 
Nucleus 11: 325-332.

RAMOS, SRR; QUEIRÓZ, MA; CASALI, VWD; CRUZ, CD. 2000. Divergência genética em germoplasma de abóbora procedente de diferentes áreas do Nordeste. Horticultura Brasileira 18: 195-199.

RESENDE, GM; BORGES, RME; GONÇALVES, NPS. 2013. Produtividade da cultura da abóbora em diferentes densidades de plantio no Vale do São Francisco. Horticultura Brasileira

$$
\text { 31: 504-508. }
$$

RESTREPO, MPV; GRISALES, SO; CABRERA, FAV; GARCÍA, DB. 2014. Variabilidade del fruto y semillas de zapallo Cucurbita moschata Duch. y Cucurbita argyrosperma subsp. sororia L. H. Acta Agronómica 63: 1-18.

RIBEIRO, AC; GUIMARÃES, PTC; ALVAREZ, VVH. 1999. Recomendações para o uso de corretivos e fertilizantes em Minas Gerais $-5^{a}$ Aproximação. Viçosa: CFSEMG. 359p.
SILVA, DJH; MOURA, MCCL; CASALI, VWD. 2001. Recursos genéticos do banco de germoplasma de hortaliças da UFV: Histórico e expedições de coleta. Horticultura Brasileira 19: 108-114.

ZITTER, TA; HOPKINS, DL; THOMAS, CE. 1996. Compedium of cucurbit diseases. St. Paul: APS. 87p. 